\title{
EL INUSITADO Y EXTRAÑO FENÓMENO VOCACIONAL DE LOS ESTUDIANTES DE LA UNIVERSIDAD DE ALCALÁ HACIA LA COMPAÑÍA DE JESÚS (1545-1634)
}

\author{
POR \\ Carlos López Pego \\ Doctor en Filosofía y Letras. Universidad Complutense
}

\begin{abstract}
RESUMEN
Basándose en un ejemplar manuscrito inédito de dos gruesos volúmenes, fechados en 1600 y 1633; «Historia del Colegio Complutense de la Compañía de Jesús» en Alcalá de Henares» se analiza el hecho de una afluencia extraordinaria de vocaciones concretamente 1190 a la recién fundada Compañía de Jesús en dicha ciudad de Alcalá entre 1543 y 1633, en su mayoría de estudiantes de la joven y abierta universidad complutense, a pesar del estereotipo cultural que no juzgaba como especialmente devotos a los estudiantes de aquel tiempo y de aquella ciudad. Se trata también, más generalmente, de las relaciones entre la dicha universidad y la Compañía de Jesús,
\end{abstract}

PALABRAS CLAVE: Universidad de Alcalá de Henares, Vocaciones, Jesuitas.

\section{THE UNWONTED AND STRANGE VOCATIONAL PHENOMENON OF ALCALÁ UNIVERSITY STUDENTS TOWARDS THE COMPANY OF JESUS (1545-1634)}

\begin{abstract}
Based on an unpublished manuscript of two thick volumes dated 1600 and 1633 entitled «History of the Complutense College of the Society of Jesus» this article analyses the fact that, between the years 1543 and 1633 an extraordinary number of vocations, namely 1190, applied for admission to the Society of Jesus just founded in the already mentioned city of Alcalá, mostly students from the young and open-minded university complutense, in spite of the fact that the stere-
\end{abstract}


otype idea was that the students in those times and in that city were not particularly pious and devotee. The relations between the above mentioned university and the Society of Jesus in general terms, are also dealt with.

KEY WORDS: University of Alcalá de Henares, Religious vocations Jesuits.

Recibido/Received 20-06-2008

Aceptado/Accepted 30-10-2008

Entre los años 1545 y 1634, 1190 personas, en su inmensa mayoría jóvenes estudiantes de la Universidad, fueron admitidos en la Compañía de Jesús de Alcalá de Henares. Pese a los fervores vocacionales en esta época hacia la vida religiosa, parece una cifra excesiva, más todavía considerando su marco sociológico concreto: los estudiantes alcalaínos.

Se trata de investigar las relaciones entre los estudiantes de la Universidad de Alcalá y el Colegio Complutense de los jesuitas entre los años de 1545 y 1634. Esta limitación cronológica se debe a que en el Archivo Histórico de la Provincia de Castilla de la Compañía de Jesús, se conserva un manuscrito fechado en al año 1.600 la primera parte y 1633 la segunda cuyo título es Historia del Colegio Complutense de la Compañía de Jesús Los autores son, respectivamente, los jesuitas PP. Cristóbal de Castro y Alonso Ezquerra.

Este manuscrito, que es la principal fuente de nuestro trabajo, consta de una primera parte escrita por Cristóbal de Castro, de 1247 páginas de 320 x 220 en dos gruesos volúmenes que cubren de 1545 a 1600 y de una $2^{\mathrm{a}}$ parte escrita por Alonso Ezquerra de 870 páginas en un sólo volumen, que cubren hasta $1633^{1}$.

De este voluminoso documento se han sacado la mayor parte de los datos que se presentarán en este artículo.

\section{EL NÚMERO DE JESUITAS EN ALCALÁ. LOS HUMILDES COMIENZOS}

La Compañía de Jesús se fundó en 1540 Por lo tanto cuando Ignacio entró en Alcalá, probablemente mediada la primavera de 1526, no era computable como jesuita. Con este presupuesto consideramos a Francisco Villanueva el primer jesuita de Alcalá. Llegó as esta ciudad en abril de $1543^{2}$. Unas señoras, an-

\footnotetext{
${ }^{1}$ Estos tres volúmenes son una copia, también manuscrita, del original, el original, que también se conserva en el mismo Archivo, consta solamente de dos volúmenes, uno para cada parte de la Historia del colegio de la Compañía de Jesús en Alcalá de Henares; el de la parte primera cuenta con 573 hojas (numeración no por páginas) y el de la segunda parte 414. El tamaño es algo mayor que el de la copia y la caligrafía mucho más vistosa y acabada.

2 Cristóbal DE CASTRO, Historia del Colegio Complutense de la Compañía de Jesús, Compluti, 1600, p. 41.

Hispania Sacra, LXI

123, enero-junio 2009, 159-190, ISSN: 0018-215-X
} 
tiguas devotas de Ignacio, le consiguen una habitación cerca de la puerta de Santiago $^{3}$ y le ponen en contacto con Pedro Sevillano estudiante gramático, de 19 años que estaba dándole vueltas con ansiedad a una posible vocación religiosa. A los pocos días de tratar con Villanueva, se decidió por la recién nacida Compañía de Jesús y en 1544 compartía, con Villanueva el mismo aposento personal de este $^{4}$. Ya eran dos los jesuitas en Alcalá, ambos alumnos de la Universidad.

Ignacio de Loyola en 1543 había escrito a Villanueva que se estableciera en Alcalá y empezara a estudiar gramática en la universidad5 5 . El P. Pedro Fabro, transmitió a Villanueva en 1545 la orden de buscar un alojamiento para un incipiente y humilde colegio en Alcalá de Henares ${ }^{6}$.

En aquellos primeros años, no se podía pensar en casas de formación que prepararan debidamente a las vocaciones que se esperaban y por otra parte tanto Ignacio como Fabro confiaban que la Universidad de Alcalá de Henares, podría ser una buena solución; tanto por la posibilidad de que surgieran vocaciones entre los estudiantes, como por la oportunidad de poder ofrecerles una buena formación filosófica y teológica.

\section{EL CRECIMIENTO RÁPIDO}

La universidad de Alcalá era todavía una institución joven, contaba a la sazón con más de tres mil estudiantes ${ }^{7}$. Concretando más, la media de estudiantes matriculados entre 1568 y 1618 fue de 3117, el pico se remontó a 3805 entre los años 1583 y 1588 .

Sobre el número de los jesuitas tenemos datos suministrados por el P. Antonio Astráin ${ }^{8}$ : y referidos al año 1547. Se acababa de constituir la Provincia de

${ }^{3}$ C. DE CASTRO, Idem.

${ }^{4}$ Villanueva fue en seguida descubierto como hombre de gran espíritu en las cosas de Dios, por varios hombres de letras de la universidad y del colegio de San Ildefonso como los doctores Lartaum, Aguilera, Miranda, Vizcaínos y sobre todo Ortiz. El Rector Zornoza concedió a Villanueva en 1543 una colegiatura en el colegio de San Isidro, y para San Lucas de 1544 el nuevo Rector Andrés Abad permitió que Sevillano viviera en el mismo aposento. Ibidem, pp. 43 y 44.

5 «que hiciera asiento en esta Universidad y con un razonable cómodo empezara a estudiar». Castro, Ibidem, p. 42.

${ }^{6}$ CASTRO. Ibidem p. 51, Fabro ordenó a Villanueva que alquilase una casilla para sí y para otros dos o tres» La «casilla» que encontraron era tan pobre sucia y abandonada que se la dejaron de balde con la única condición de que la limpiaran, era llamada «patio de Mataperros», y de resultas del trabajo de la limpieza, enfermaron todos los jesuitas gravemente, con la sola excepción de Villanueva.

7 Según datos que se basan en los libros de matrícula recopilados por Benoit PELLESTRANDi y Luis Miguel GutiÉRrez TORRECILla en su estudio Libro de matrícula de la Universidad de Alcalá publicado en Cisneros y el Siglo de Oro de la Universidad de Alcalá, Alcalá de Henares, 1999, p. 171.

${ }^{8}$ A. Astráin. Historia de la Compañía de Jesús en la Asistencia de España, vol I, p. 248, nota 1. 
España con 42 jesuitas que se distribuían en 6 casas y era la de Alcalá la que contaba con una comunidad más numerosa. Estos eran los datos

$\begin{array}{lr}\text { Alcalá } & 12 \\ \text { Gandía } & 10 \\ \text { Valencia } & 7 \\ \text { Barcelona } & 6 \\ \text { Madrid } & 4 \\ \text { Valladolid } & 3\end{array}$

El crecimiento fue tan rápido que en el año 1553 escribía Ignacio al P. Jerónimo Nadal, dándole orden para proceder a una división de la Provincia de España. Se subdividiría en tres provincias, Andalucía, Aragón y Castilla. Esta última ocuparía las dos mesetas y tendría como Provincial al P. Araoz. Alcalá con 35 sujetos seguía siendo la casa más numerosa de Castilla9 ${ }^{9}$. Astráin publica los nombres de estos 35 tomados del primer catálogo que se publica de los jesuitas de España en ese mismo año ${ }^{10}$.

\section{REPARTIENDO VOCACIONES}

En los años sesenta del siglo XVI, durante el generalato de Francisco de Borja era tal la afluencia de vocaciones universitarias, que, por falta de sitio, había que enviarlas a otras casas de formación:

La Provincia [de Toledo] después de proveerse bien, ofreció postulantes a otras provincias. Aunque está falta de obreros [operarios sacerdotes ya formados] que este año ha sido fértil de ellos a gloria de Dios, desde la cuaresma acá se han recogido una docena de ellos de gente tan escogida cuanto jamás ha entrado aquí, y con todo esto está la Universidad tan alborotada y otra gente tan movida, importunando por la entrada que de bachilleres en Artes y de otros que no han acabado sus cursos hay otro mucho mayor número, que aunque se les da esperanza para adelante, pero todavía, habiendo donde metellos, no sería mal asegurallos y así he escrito a algunas provincias de por acá si quieren gente».

En 1587 seguía siendo Alcalá la casa mayor de la Provincia de Toledo con 112 jesuitas. Este fue probablemente el mayor número alcanzado, ya que en

${ }^{9}$ Los jesuitas de Salamanca eran 22 en 1551, en 1562 las numerosas vocaciones a la Compañía de Jesús procedentes en su mayoría de las dos universidades mayores de Alcalá y Salamanca permitieron una nueva división de la provincia de Castilla, nació la provincia de Toledo con los territorios de «aquende los puertos»y la provincia de Castilla mantuvo su nombre con las tierras de «allende los puertos». A. Astráin, Ibidem, pp. 300 y 401.

${ }^{10}$ A. Astráin, Ibidem, pp. 409-410.

Hispania Sacra, LXI

123, enero-junio 2009, 159-190, ISSN: 0018-215-X 
1593 eran 99 y en $161183^{11}$. Se trataba de una comunidad muy numerosa. Por lo que parcialmente tenemos que concluir que el número de los estudiantes que entraron en la Compañía de Jesús en la segunda mitad del siglo XVI fue verdaderamente espectacular.

\section{UN NÚMERO VERDADERAMENTE ESPECTACULAR}

El P. Castro al finalizar su trabajo sobre la primera parte de su Historia valora este punto con cierta solemnidad y énfasis, incluso en la presentación caligráfica:

Han sido recibidos en este Colegio de Alcalá para la Compañía desde que entró en la Universidad el Hermano Francisco Villanueva fundador de este Colegio el año de 1543 hasta este de 1599, 770, 18 doctores, uno de ellos Abad de Santi Yuste, cuarenta maestros y treinta y ocho licenciados y los demás de menores grados ${ }^{12}$.

Tal vez Castro ha sumado todos los que entraron en esta época sin descontar a los sacerdotes ya formados, procedentes de otras poblaciones, ni a los hermanos coadjutores ${ }^{13}$. Sin embargo los datos que se nos suministran en la primera y segunda parte de su Historia sí permiten afirmar que el número de las vocaciones de estudiantes y aun profesores de la Universidad que entraron en la Compañía de Jesús fue ciertamente de muchos centenares. De aquí el agradecimiento entusiasta que muestra hacia la Universidad de Alcalá desde el primer capítulo de su obra:

Esta Universidad de Alcalá ha sido desde sus principios como madre de la Compañía ${ }^{14}$.

Castro, con la perspectiva de estos primeros cincuenta años de la vida de los jesuitas en Alcalá, considera una especial providencia de Dios la existencia de la Universidad de Alcalá para la fundación del Colegio de los jesuitas. Por lo que así titula el primer capítulo de su obra:

Como Dios proveyó de la Universidad de Alcalá para la fundación del Colegio de la Compañía.

\footnotetext{
11 Se han consultado en el Archivo Histórico de la Provincia de Castilla, los catálogos trienales de los años 1587, 1593 y 1611, así como los datos existentes en el legajo c-386-1.

12 CAstro, Ibidem, p. 1249.

${ }^{13}$ Los hermanos coadjutores no existieron en los primeros años de la Compañía de Jesús, fueron aprobados en 1546 por un breve de Pablo III. En la práctica no se admitió a ninguno antes de 1553 y hasta 1556 solo entraron 13 en toda la Compañía de Jesús. E. Olivares en Diccionario Histórico de la Compañía de Jesús, Madrid, 2001, tomo III, p. 2666.

14 CAstro, Ibidem, p. 3.
} 
Independientemente del barroquismo hiperbólico con que puedan juzgarse estas manifestaciones hay un fundamento real, que es el apoyo que encontraron los jesuitas en la Universidad.

Este apoyo se manifestó sobre todo en las vocaciones de estudiantes y, durante bastante tiempo, en la formación de los mismos ya que una Compañía de Jesús, recién fundada, carecía de medios para la formación de sus hombres. Estos procedían de la Universidad y en ella siguieron formándose durante bastantes años. Igualmente la Compañía pudo encontrar un apoyo institucional en la Universidad a la hora de solucionar algunos graves problemas ${ }^{15}$.

El inicio de la presencia de los jesuitas (1545) en Alcalá fue enormemente humilde tanto en medios personales como económicos. La sospecha de novedad, a veces tachada de luteranismo o iluminismo, les acompañaba. Todo cambió muy rápidamente a partir de 1546, año en el que el P. Araoz predicó en San Ildefonso con tal acierto que desde entonces se empezó a mirar bien al pequeño y desarrapado grupito de jesuitas.

El grupo que empezó siendo de dos, Villanueva y Sevillano pronto aumentó hasta llegar a siete gracias a pequeños refuerzos que Ignacio les envió de Portugal y de Roma pero rápidamente empezaron a solicitar su entrada en la Compañía alumnos de la Universidad.

En 1548 parece que se inicia una nueva etapa. Piden unirse a la compañía ocho estudiantes movidos por el buen ejemplo que ven en los pocos jesuitas de la universidad ${ }^{16}$. El año 1550 son ya 12 los que entran movidos varios de ellos por la predicación del P. Estrada17. Del año 1551 se dice que entran muchos de la universidad, "de tal manera que no hay posibilidad de admitir a todos los que se mueven a ello, por falta de sitio y de medios» (Castro, p. 165) ${ }^{18}$. Entran seis en 1552 y a partir de este año se da regularmente noticia del número de los que son recibidos cada año, especificándose algunos datos, los que juzga el autor más significativos o importantes, teniendo también en cuenta el desarrollo posterior de la vida de cada uno de ellos en la Compañía, a veces extendiéndose por un capítulo entero o por varios.

En la segunda parte de la Historia, obra ya del P. Alonso Ezquerra, no solamente figuran los datos numéricos de los que entran cada año sino que hay rela-

\footnotetext{
15 Ataque a los Ejercicios espirituales, Persecución a los jesuitas del Arzobispo Siliceo, Controversia de Auxiliis, etc.

${ }^{16}$ CASTRO, Ibidem, p. 124.

${ }^{17}$ CAstro, Ibidem, p. 129. El P. Francisco de Estrada no era de los jesuitas de Alcalá, pero se le invitó para que predicara en la Universidad en Adviento y Cuaresma, lo hizo causando gran impacto espiritual a los estudiantes, como lo había hecho antes en las Universidades de Lovaina, Coimbra y Salamanca.

18 Desde esta nota en adelante los datos numéricos de los ingresados cada año figurarán incorporados al texto, no en notas a pie de página.

Hispania Sacra, LXI

123, enero-junio 2009, 159-190, ISSN: 0018-215-X
} 
ción nominal de todos ellos, a la que se añade, según la importancia histórica que se atribuye a cada sujeto una reseña de mayor o menor extensión. Como mínimo figuran, aparte del nombre y apellido la edad, la situación académica y social, el sitio de origen con nombre del pueblo y parroquia y a veces algún párrafo más sobre la vida de ese sujeto en la Compañía, con una extensión muy variable.

En Apéndice al final de este artículo se presentarán ordenadamente todos estos datos. Pero juzgamos de interés el presentar aquí un párrafo que con motivo de la muerte del P. Villanueva, fundador de este colegio, en 1557, se resumen por Castro los datos hasta dicha fecha.

Fueron los recibidos en Alcalá desde que el P. Francisco de Villanueva vino a esta Universidad, hasta el año 1557, en que murió, 144 sugetos (sic) de grandes partes e ingenios, aptos para todo género de letras y mucho de ellos ya letrados consumados porque los doce de ellos entraron ya hechos Doctores que son los PP. Miguel de Torres colegial mayor de Alcalá, Juan de Montoya, Pisa, Salinas, Parra, Placa y Antonio Sánchez colegial de Sigüenza, Rodríguez, Santander y Ramírez y dos doctores in utroque jure Diego del Castillo y Pedro de Saavedra catedrático de Cánones de Alcalá y diez graduados de menos grados pero todos de grandes habilidades. (Castro pp. 584 y 585).

\section{ESTA ABUNDANCIA DE VOCACIONES PERMITIÓ UNA NOTABLE EXPANSIÓN}

Tal abundancia de vocaciones, prolongada durante muchos años, permitió la expansión de la Compañía de Jesús en España y aun fuera de ella. Desde Alcalá se fundaron directamente varios colegios por medio de los jesuitas que de la Universidad entraron en la Compañía.

Villanueva, desde su cargo de rector de Alcalá fundó los colegios de Córdoba, Plasencia y Cuenca.

El P. Doctor Miguel de Torres fundó el de Salamanca.

El P. Pedro Sevillano los de Medina, Belmonte y Huete.

El P. Valderrábano el de Monterrey.

El P. Pablo Alvarez el de Granada.

El P. Hernando Alvarez el de Avila.

El P. Diego Carrillo el de Ocaña.

El P. Bartolomé Bustamante el de Trigueros en Andalucía ${ }^{19}$.

Las fechas de entrada en el noviciado eran variables ${ }^{20}$. Con el tiempo fueron cada vez concentrándose a principios de marzo, debido a los efectos de la predi-

\footnotetext{
${ }^{19}$ CASTRo, Ibidem, p. 585.

20 También lo eran las fechas de matriculación en la universidad, según Luis Miguel GuTIÉRREZ TORRECILla en su artículo sobre El libro de Matrícula de la Universidad de Alcalá publicado en Cisne- 
cación cuaresmal que removía las conciencias de muchos estudiantes y los empujaba hacia la vida religiosa o hacia la realización de ejercicios espirituales para ordenar su vida hacia las eventuales llamadas de Dios a una vida consagrada ${ }^{21}$.

En varias ocasiones a lo largo de la Historia del Colegio Complutense se considera la conducta de los jesuitas alumnos de la universidad como un ejemplo atrayente para sus compañeros que se sentían llamados a imitarlos ${ }^{22}$.

Es curioso que a partir de 1631 el P. General de la Compañía, el veneciano Mucio Vitelleschi, limita por razones económicas ${ }^{23}$ el número de admisiones de cada provincia:

Las grandes cosechas de los recibidos de los años pasados y las grandes penurias que en ellos hubo de dinero respecto de las mudanzas de la moneda obligó a nuestro Padre General a limitar las licencias sobre el recibo de sujetos ${ }^{24}$.

Estas disposiciones del general, repercutieron en la práctica en que sólo se pudieran recibir cuatro vocaciones en Alcalá en los años 1632 y 1633 (pp. 725 y 734).

Sin embargo no deja de ser un hecho palpable la más que considerable afluencia de jóvenes universitarios que llamaron a las puertas de la Compañía de Jesús durante la segunda mitad del siglo XVI y el primer tercio del siglo XVII.

Ante este hecho indiscutible podemos preguntarnos, ¿Era la Universidad de Alcalá de aquellos tiempos terreno abonado para que surgieran en ella tantas vocaciones?

\section{LOS ESTUDIANTES DE ALCALÁ «TRAVIESOS», «VALIENTES» Y OTROS}

Ya hemos hablado del colectivo de los estudiantes de Alcalá y de su cantidad que llegó a acercarse en estos años a los cuatro mil estudiantes. Era la segunda

ros y el Siglo de Oro de la Universidad de Alcalá, Alcalá de Henares 1999, «no habia una fecha ni periodo fijado para matricularse, los estudiantes según llegaban se dirigían al oficial del secretario para matricularse, los primeros en el mes de octubre, la mayoría a principios de noviembre aunque son bastantes los que se inscribían en los meses posteriores».

${ }^{21}$ Esta predicación solía estar a cargo de predicadores muy escogidos, como lo fueron el P. Araoz en 1547 y el P. Estrada en 1550, pero en los años posteriores intervinieron otros también altamente cualificados como, por ejemplo, y citando siempre a Castro, el P. Antonio de Madrid (p. 804), el P. Govierno (pp. 886 y 922) P. Ramírez (p. 951) y Jerónimo de Florencia (p. 744).

${ }^{22}$ Así se afirma explícitamente en la obra de Castro en 1548 (p. 124); 1565 (p. 909); 1569 (p. 1068) 1571 (p. 1098).

${ }^{23}$ Eran los años del periodo inflacionista al que Vicens Vives llamó la evolución cuprífera en su. Historia Económica de España. Barcelona, 1979, p. 42.

${ }^{24}$ Alonso EzQuerra, Historia del Colegio de Alcalá. Segunda parte 1630-1633. Manuscrito p. 711.

Hispania Sacra, LXI

123, enero-junio 2009, 159-190, ISSN: 0018-215-X 
Universidad del Reino después de Salamanca y seguida de Valladolid, las tres Universidades «Mayores» 25 , las que más fácilmente aseguraban puestos relevantes en la administración del Reino o de la Iglesia.

Alcalá era por aquel entonces una villa, señorío del Arzobispo de Toledo, con unos dos mil vecinos cuyas relaciones con los más de tres mil estudiantes distaban mucho de ser cordiales; eran frecuentes las pendencias entre unos y otros; a los gritos de ¡Favor al Colegio! y ¡Favor a la Villa! salían al aire espadas y puñales o resonaban pistolas y arcabuces ${ }^{26}$. Es verdad que eran numerosos los conventos y casas de religiosos, atraídos por la misma universidad, pero esto no significaba una proclividad de los estudiantes hacia lo espiritual y religioso ${ }^{27}$.

El elemento desgarrado y vano de los estudiantes de Alcalá se había manifestado muy claramente desde los comienzos de la Universidad.

Cuando el rey católico Fernando visitaba este centro en enero de 1516; en su acompañamiento figuraba un grupo de pajes del Rey, todos ellos de familias de la alta nobleza. «No se distinguían los retoños de la alta aristocracia de aquel entonces por un especial respeto hacia lo universitario», cosa de clérigos y segundones, nobleza menor, «labradores honrados»y de ahí para abajo ${ }^{28}$ por ello empezaron a burlarse de los estudiantes lo que tuvo sus consecuencias.

«No eran ni son los estudiantes para aguantar mucho, por muy nobles que fueran los pajes y sus padres, y como a las burletas añadian el quemarles el pelo con las hachas, arremetieron contra los mal criados palaciegos que lo pasaran mal si no hubiera mediado el Conde de Coruña D. Bernardino» ${ }^{29}$.

Hay dos palabras en la literatura de la época que tienen un sentido muy diferente del actual, son los adjetivos. «travieso» y «valiente». Las travesuras eran de grueso calibre, novatadas crueles y aparatosas, robos, engaños, violaciones

\footnotetext{
${ }^{25}$ Margarita TORRemocha, La vida estudiantil en el Antiguo régimen, Madrid 1998, p. 4 y Luis E. Rodríguez-San Pedro Bezares, Universidades del Barroco o de la Monarquía Católica. Madrid 2001, p. 479.

26 Joaquín de EnTrambasaguas, Grandeza y Decadencia de la Universidad Complutense, Madrid 1996, p. 94.

27 Astráin. Ibidem Tomo I, p. 257. Comenta Astráin cómo Cristóbal de Mendoza, uno de los dos jesuitas que envió Ignacio desde Roma al recién nacido colegio, viendo, el entusiasmo que causó entre los estudiantes la predicación del P. Araoz en la cuaresma de 1547 hizo el siguiente comentario «Tanta gente seguir al predicador aquí en esta universidad es cosa que nunca fácilmente se ve».

${ }^{28}$ L. E. Rodríguez-SAn Pedro Bezares, Ibidem, pp. 502-503, refiriéndose a ciertos aspectos sociológicos de la universidad de Salamanca, a comienzos del siglo XVII contabiliza solo a un número bastante reducido de «nobles generosos» matriculados anualmente. A comienzos del siglo XVII, solamente entre 10 y 30 al año, número que se contrapone a los 600-700 matriculados en Colegios y Conventos y a los 3.500-4200 manteístas no colegiales.
}

29 J. ENTRAMBASAgUAS, Ibidem, p. 88. 
en cualquier sitio privado o público (muchas veces por no poder disponer de privacidad) palabras de matrimonio no cumplidas o maridos consentidores por dinero y un largo etcétera.

Tampoco la palabra valiente constituía un elogio, más bien significaba con frecuencia una arrogancia pendenciera que se traducía en agresividad, actos de violencia individuales o colectivos contra los alguaciles o los habitantes de la villa, o entre diversas facciones de estudiantes. En estas ocasiones no hablaban solamente los puñales y las espadas sino también pistolas y arcabuces, con resultados de muerte o heridas graves. Llegaron a realizarse más de una vez, asaltos a las cárceles para liberar a presos, aun a condenados a muerte, sin respetar ni a profesores de la universidad ni a los mismos rectores. Especial relieve tuvieron los enfrentamientos entre vecinos y ciudadanos hasta el punto de haberse tratado, en algunas sesiones de claustro, del traslado de la Universidad a Madrid, así lo afirma Emtrambasaguas ${ }^{30}$, lo que no se hizo en esta época, en parte por la fuerte oposición de las autoridades locales de la Villa y Corte que temían a los estudiantes como una peste.

José Luis Peset y Elena Fernández Sandoica, en su obra «Estudiantes de Alcalá» nos ilustran con muchos y muy variados ejemplos de esta acusada violencia de los estudiantes alcalaínos ${ }^{31}$. Por su parte, Margarita Torremocha cita curiosamente una declinación aducida por Covarrubias como el «Latín» de los estudiantes ${ }^{32}$ :

Nominativo: Juego

Genitivo: Taberna

Dativo: Ramera

Acusativo Pobreza

Vocativo Ladrón

Ablativo Horca

A este desmadre permanente y a este estado de violencia compulsiva pudieron contribuir los amplísimos poderes concedidos en sus estatutos a los estudiantes de las grandes universidades de Castilla y muy especialmente a la de Alcalá.

La permisividad rayaba a veces en una casi total impunidad, para los delitos de los universitarios. Esto es punto en el que suelen coincidir los historiadores especializados en la vida estudiantil de aquellos tiempos. Suele citarse una frase del Cardenal Cisneros; al ser informado de determinados desmanes estudiantiles afirmaba: «Es la espuma de la ebullición escolar que pronto apagará sus ardores» ${ }^{33}$.

\footnotetext{
30 J. EMTRAMBASAGUAS, Ibidem, p. 96.

31 J. L. Peset y E. F. SANDOiKa, Estudiantes de Alcalá, Alcalá de Henares 1980, p. 63 y ss.

32 Margarita TORREMOCHA. «La vida estudiantil en el antiguo régimen», p. 4.

33 J. ENTRAMBASAGUAS, Ibidem, p. 92.
} 
Sin embargo los estudiantes no carecían en su inmensa mayoría de un fondo religioso y un instintivo respeto hacia las cosas de la Iglesia. Margarita Torremocha lo hace notar en su obra ya citada ${ }^{34}$ : «La religiosidad de los estudiantes era, con algunas excepciones, en general respetuosa con lo religioso como en la sociedad de su tiempo».

¿Hubo Sintonía entre los estudiantes de AlCAlá y la naCiente Compañía DE JESÚS?

Ante el hecho de la rápida multiplicación, de las vocaciones a la Compañía de Jesús en Alcalá de Henares se puede suponer que se dio una especial sintonía entre la Compañía de Jesús y los estudiantes y profesores de Alcalá.

En los primeros comienzos, como ya hemos hecho notar, no fue así, flotaba en el ambiente alcalaíno eclesiástico, civil y universitario una desconfianza contra esos pocos y desarrapados religiosos de una orden nueva que no tenían rezo del coro, como el resto los anteriores religiosos, ni ayunos ni penitencias programadas. La sospecha de iluminismo estaba al cabo de la calle pero según Castro fue disipada con una rapidez espectacular por los sermones del P. Araoz desde el púlpito de San Ildefonso. Araoz «hacía el oficio de Provincial»35 y el día 14 de septiembre de 1546 día de la Exaltación de la Santa Cruz empezó sus sermones con tal acierto que desde entonces «se formó alguna más noticia de la Compañía en la Universidad y la gente fue desechando algunos recelos que de los de ella tenía».

El P. Cristóbal de Mendoza, enviado desde Roma por San Ignacio, como un ligero refuerzo para el pequeño grupo de jesuitas de Alcalá (en aquel año con ellos llegaron a siete) comentando estos sermones de Araoz escribía:

Tal es la noticia que de nosotros dio en esta universidad, que donde quasi estaban escondidos, quiero decir que no nos conocían ahora nos conocen tanto que cuando sale algún hermano lo van mirando y diciendo Ecce ex illis est (este es de ellos) ${ }^{36}$.

Se daban también probablemente causas más generales y profundas favorecedoras para los jesuitas no sólo en Alcalá, sino también en todos los reinos de España; Martínez Millán se refiere a la protección que dispensaba a los jesuitas la infanta Doña Juana, regente del reino durante cinco años, y con ella todo el partido ebolista ${ }^{37}$. Esta protección se materializó más explícitamente en la casa

\footnotetext{
${ }^{34}$ Margarita TORREMOCHA, Ibidem, p. 271.

35 CASTRO, Ibidem, p. 61.

36 ASTRÁIn, Ibidem, tomo I, p. 257.

37 J. Martínez Millán, La Corte de Felipe II, Madrid 1994, pp. 80-92.
} 
de Alcalá, por las frecuentes estancias en esta ciudad de las infantas y la particular intervención de Doña Leonor de Mascareñas, noble dama portuguesa de la Corte de Carlos V y aya de las infantas ${ }^{38}$. Pero en toda España se notó la protección política de la «sangre real».

Según el ya citado Martínez Millán, la Compañía de Jesús fue gran protagonista de la Historia Moderna a la luz de las tendencias espirituales internas a las altas esferas de la sociedad española; opinión que recoge también Michele Olivari ${ }^{39}$. «Desde Andalucía a Galicia, desde Almería a Cataluña hubo obispos, capítulos, canónigos individuales, intelectuales, aristócratas, burgueses y magnates urbanos que compartieron con calor las preferencias de la gobernadora del reino y de los grupos de poder que les apoyaban». Pero Olivari va más lejos, el apoyo de la sangre real no hubiera bastado a la Compañía si la sensibilidad religiosa de los súbditos, no hubiera respondido de un modo extraordinario en ciudades y localidades por toda la geografía española ${ }^{40}$. De la misma opinión es Tellechea según el cual no se trataba de un movimiento unívoco de lo alto a lo bajo «Innumerables fuentes, no sólo de la Compañía de Jesús, atestiguan los apoyos a los jesuitas de la gente común de las ciudades y del campo» ${ }^{41}$.

Volviendo al estudiantado de aquella época, así nos lo describe Luis Enrique Rodríguez-San Pedro, refiriéndose más bien al estudiantado de Salamanca, que, desde un punto de vista sociológico, se puede suponer como bastante similar al de Alcalá de Henares:

«Desde la aristocracia nobiliar de titulados, una escala descendente recorre el gremio de estudiantes, pasada por las clases medias nobiliarias o burguesas, hasta los pequeños hidalgos, rentistas de cierta holgura, campesinos y menestrales en búsqueda de promoción, pobres, criados y pícaros».

El importante tema del alojamiento encontraba diversas soluciones. Eran minoría los que obtenían una beca o colegiatura en los colegios, mayor y menores, en los que no faltaban reglamentos o estatutos que organizaban o intentaban organizar la vida estudiantil con todo detalle. Menor control, aunque alguno, se daba en los pupilajes; pequeños grupos de estudiantes bajo la autoridad de un tutor, generalmente bachiller. La variedad de situaciones creaba también variedad de oportunidades, como las de alojamientos en casa familiar o de un amigo. Margarita Torremocha se refiere a los muy numerosos que vivían al servicio de otros ${ }^{42}$, los llamados capigorristas, y a los de habitación alquilada, y a

\footnotetext{
38 CASTRO, Ibidem, p. 53.

${ }^{39}$ Michele OLIVARI, Entre el trono y la opinión, Salamanca. 2004, p. 18.

40 Ibidem, p. 146.

${ }^{41}$ I. Tellechea Idígoras, Tiempos Recios, Salamanca 1967.

42 Margarita TorRemocha, Ibidem, pp. 99 y 104.
} 
las «repúblicas» o «compañías»; grupos de estudiantes que vivían juntos pagando un local, y organizaban su vida libremente.

Existe un tópico sobre las dificultades de los estudiantes de aquellos siglos para comer. La literatura picaresca y el mismo Cervantes rememoran las hambres de los estudiantes. En Alcalá, a los estudiantes del Colegio de San Ambrosio se les solían gastar bromas hablándoles del colegio «de San Hambrosio» aspirando notablemente la «h», pues era, o fue proverbial durante alguna época, la escasez de comida en dicho colegio.

En general puede afirmarse que pese a los frecuentes apuros pecuniarios los estudiantes no eran generalmente pobres y normalmente acababan por salir adelante.

Peset termina su libro «Estudiantes de Alcalá» con el siguiente párrafo:

«Tal es la realidad del estudiante, no todos son pobres y son muy pocos los que de verdad dejan de comer o de tener cobijo. La Universidad fue siempre madre acogedora y de ella obtuvieron siempre los estudiantes saberes, morada y protección. A veces en ella la vida fue dura, pero sin duda siempre compensó a quienes acudieron a sus aulas en busca de santidad oficio o beneficio».

A las razones que se pueden deducir de este somero análisis, podemos, añadir algunas consideraciones.

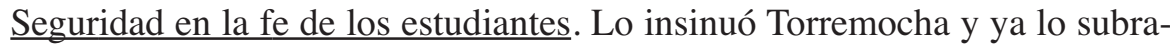
yamos en nota.. Los pendencieros «valientes» cuando un lance desgraciado resultaba mortal, la víctima, si podía, o su agresor, a gritos pedían confesión.

El carisma de Villanueva, especialmente para dar ejercicios espirituales a cualquier tipo de personas. Ya nos hemos referido a él, carecía de formación aun elemental, justamente sabía leer y las cuatro reglas, pero Ignacio en los últimos años de su vida lo juzgaba, como el tercero de toda la Compañía de Jesús en esta materia, después de Fabro y Salmerón ${ }^{43}$. Con Villanueva hicieron ejercicios bastantes de los que entraban en la Compañía.

La austeridad y pobreza en grado extremo de los primeros jesuitas de Alcalá que reforzaba el trato sencillo de los jesuitas con otros estudiantes. Es posible que la ligera pero significativa disminución de vocaciones que se nota desde los últimos años del XVI pueda deberse a la disminución en el trato entre los uni-

${ }^{43}$ El primer destino de Villanueva fue la casa de Coimbra, su salud empeoró y el provincial de Portugal Simón Rodríguez se quejó a Ignacio de que le enviara jesuitas de mucha edad, poquísima formación y salud quebrantada como Villanueva. Ignacio, refiriéndose a este afirmó:

"Que si lo tratase y conociese hallaría en él las partes necesarias para lo que se pretendía en Portugal y que de sesenta estudiantes que entonces había en la Compañía él se contentaría con que acabados los estudios, los veinte fueran como Villanueva», CASTRO, página 40. 
versitarios y los estudiantes jesuitas a medida que se iban impartiendo las clases por los mismos jesuitas en su propio colegio, con lo que bastantes dejaban de asistir a la Universidad ${ }^{44}$.

El espíritu misionero de la Compañía que sintonizaba, en aquellos tiempos de descubrimientos, exploraciones, Imperio, con los jóvenes estudiantes ${ }^{45}$ de Alcalá.

Todas estas concausas nos permiten responder afirmativamente a la pregunta que formulábamos arriba sobre si era la Universidad de Alcalá y sus estudiantes terreno abonado para proporcionar tantas vocaciones a la Compañía de Jesús.

Los entrados a la Compañía de Jesús en AlCalá. Descripción general con ALGUNOS EJEMPLOS

\section{a) Procedencia geográfica y social}

Desde un punto de vista geográfico las vocaciones proceden muy principalmente de la diócesis de Toledo, aunque abundan también, relativamente, los de Sigüenza, Calahorra, Pamplona, Alava y Murcia. Algunos pocos extranjeros Francia, Inglaterra, Escocia, Sicilia, Portugal (aunque estos últimos no con la numerosidad con que afluían a la universidad de Salamanca).

Sociológicamente entraron algunos, pocos, de la alta nobleza ${ }^{46}$, bastantes de los que simplemente se afirma, «de padres nobles»; una clara mayoría de «labradores honrados», pocos comerciantes, bastantes criados y pajes y menos trabajadores de la construcción o de los servicios.

\section{b) Adolescentes, jóvenes y mayores}

Las edades fueron muy variables; los había jóvenes gramáticos de 15 o 16 años, como Ripalda (Castro 179-182), el del famoso catecismo, que entró con 15 años no cumplidos. Sus padres intentaron sacarlo y consiguieron del Conse-

\footnotetext{
44 Se empezó a ello timidamente en 1560 con el P. Deza.

45 Jóvenes jesuitas procedentes de la Universidad fueron enviados a Méjico, Perú, Filipinas, China o participaron como capellanes en Flandes, Lepanto. La «Invencible», la escuadra de Cartagena contra la piratería, etc. y llegaron algunos a ocupar cátedras, en Roma y París.

${ }^{46}$ Como Iñigo López de Mendoza, hijo del Marqués de Mondéjar que entró en 1601 (EzQuERRA, p. 16); Pedro de Manrique el año 1573, hijo del Adelantado de Castilla, (CASTRO, p. 1136). Rodrigo Niño, hijo del Conde de Villaverde, entró en 1589 (EzQUERRA, p. 614) Nicolás de Almazán en 1570, de la familia del Duque de Medinaceli (EzQuerra, p. 716).

Hispania Sacra, LXI

123, enero-junio 2009, 159-190, ISSN: 0018-215-X
} 
jo Real un arbitraje presidido por el rector de la Universidad, que era aquel año de 1551 el Maestro Domingo Roldán. El adolescente Ripalda se defendió con sabiduría ante el tribunal de arbitraje, y logró que el Rector quedara tan convencido de su vocación, que no sólo le apoyó sino que le ofreció alguaciles para que le acompañaran a la casa de los jesuitas sin que lo raptaran algunos hombres apostados por su familia para hacerlo, Jerónimo Ripalda rehusó la ayuda «soy muchacho y puedo correr», y pudo llegar contento a su noviciado.

Caso muy distinto fue el de aquel otro de 14 años, tal vez el más joven de los novicios entrados en Alcalá. Se llamaba Bernardino de Velasco, entró en 1577 (Castro, p. 1202).

«fue recibido a nueve de mayo muy niño y muy delicado por haber sido criado con grande regalo por su tía Isabel de Osorio que le quería con extremo».

Estos mimos tuvieron serias consecuencias, el novicio no se atrevía a estar solo en su aposento, ni andar por pasillos oscuros. Superó por las bravas estas serias dificultades encerrándose una noche entera, a petición propia, en una capilla en la que había un esqueleto y aquella noche venció para siempre sus temores y aseguró su vocación.

En el extremo contrario tenemos personas adultas, bastante adultas. Como por ejemplo el Doctor Pedro de Saavedra que entró en la Compañía de Jesús en 1556 a los 46 años de edad. Había nacido en Esquivias, estudiado leyes en Salamanca, explicado cánones en Alcalá, llegado a ser alto funcionario del Arzobispado de Toledo, casado, padre de dos hijas, viudo, rector de la Universidad de Alcalá, catedrático de la misma y, finalmente, experimentó su vocación a la Compañía (Castro, pp. 479 y ss).

No fue este el único rector de la Universidad de Alcalá de Henares que entró en la Compañía de Jesús ${ }^{47}$. Hubo bastantes desde los comienzos, como el famoso P. Torres que, por encargo expreso de Ignacio de Loyola, fundó siendo todavía novicio, el colegio de jesuitas de Salamanca.

Tenemos un ejemplo notable en Pedro Sánchez. Había nacido en 1526 y entró en el noviciado de Alcalá en 1558, pero ya había realizado con éxito notable estudios de Artes y Teología, había sido Colegial Mayor, Rector de la Universidad, y a la sazón era Catedrático de Artes. Pidió permiso al Rector para entrar en la Compañía, le acompañaron en su entrada al Noviciado éste mismo en persona y varios profesores y alumnos (Astráin II, p. 63, Castro, p. 642 y ss.). Más

${ }^{47}$ Los estatutos de la Universidad de Alcalá establecían que el rector se elegía por un año, el día de San Lucas, tenía que ser uno de los estudiantes del Colegio Mayor San Ildefonso, y generalmente era ya Doctor o Maestro en Artes o colegial muy avanzado y en muchos casos ya sacerdote. Fueron bastantes los que entraron en la Compañía habiendo sido ya rectores y alguno hasta siéndolo. 
adelante en 1572 Pedro Sánchez era nombrado por Francisco de Borja, fundador y primer Provincial de los jesuitas de Nueva España (México).

Más notable todavía fue el caso de Pedro de Balbás abad de Santi Yuste, tal vez fue la vocación académicamente más valiosa, sus estudios en la Universidad de Alcalá fueron extraordinariamente brillantes.

\begin{abstract}
«... pasando en sus estudios por todos los colegios de Artes y Teología, y por los grados de sus facultades, siempre llevó el primer lugar como también los primeros premios en todo género de composiciones, griegas, latinas, hebreas y poéticas, que en todas le daban todas ventajas. Leyó curso de Artes, fue Rector de la Universidad y leyó primero la cátedra de Teología de Durando y al fin la prima de Santo Tomás y vino a alcanzar todo lo que en la Universidad se podía alcanzar, pues vino a ser Cancellario y Abad de San Juste».
\end{abstract}

Sintió vocación en unos ejercicios espirituales en 1562, experimentó resistencias, dudas y vacilaciones, que se prolongaron en el tiempo e hicieron dudar también algo a los Superiores de la orden, pero al final lo vio claro y insistió de tal manera que fue admitido finalmente en la Compañía en 1572. Sus ejemplos de humildad llamaron poderosamente la atención en la Universidad y en toda la ciudad. Falleció inopinadamente a los tres meses de noviciado con una enfermedad llamada entonces tabardillo y ahora difteria (Castro, p. 1.108 y ss).

Entre las vocaciones que entraron el año 1624, que fueron 7, hubo una verdaderamente singular la de Alvaro de Ayala, hijo del conde de Fuensalida, licenciado en cánones, Colegial Mayor y Rector de la Universidad, entró el día 6 de noviembre y ese mismo día falleció con extraordinario consuelo viendo cumplidos sus deseos aunque tan tarde ${ }^{48}$. Álvaro de Ayala murió a las pocas horas de ingresar en la Compañía de Jesús, Tuvo probablemente el noviciado de menos duración en toda la Compañía de Jesús.

\title{
c) También había sitio para los «traviesos» $y$ «valientes»
}

Juan de Carrera, «Hombre de gran persona y muchas fuerzas y que entre los estudiantes era tenido por el más valiente que había en Alcalá» (Castro 235) entró a los 26 años en 1552 después de pensarlo, sintiendo mucha repugnancia y dudas y ayudado por los consejos de su Maestro el Doctor Carrillo catedrático de Cánones, no sin superar lo que él creía una aparición del diablo, con el que «pareciéndole que allí le valdría su valentía, tomo una espada y acuchillose con él».

${ }^{48}$ EZQUERRA, Ibidem, p. 542.

Hispania Sacra, LXI

123, enero-junio 2009, 159-190, ISSN: 0018-215-X 
A este mismo género de «los traviesos y valientes» de capa y espada perteneció el hermano Luis Ruiz (Castro, 754-782). Era el más pequeño de siete hermanos, y por la viudez temprana de su madre se vio obligado desde muy niño a trabajar para ayudar a sustentarla. Estuvo al servicio de distintos señores y cayó muy bien con todos ellos especialmente con el Duque de Guadalajara. Obtuvo la protección de todos, por la simpatía verdaderamente arrolladora de su carácter. Varias veces tuvo impulsos para entrar en la Compañía, pero nunca lo quisieron admitir «desechándole por niño y travieso».

Gracias a sus protectores consiguió medios para estudiar, primero gramática, y después ya Artes en la universidad. Su simpatía no estaba siempre acompañada de prudencia, y menudeaban sus travesuras, y él seguía sintiendo llamadas de Dios a la vida religiosa. I intentaron atraerle religiosos de más de una orden, pero la gravedad creciente de «sus travesuras» le empujaron a una frialdad religiosa que le llevaba a insistir intencionadamente en el desorden de su vida, precisamente para ahuyentar su vocación.

«él mismo hacía tales cosas que cerraba la puerta para no ser recibido... tenía muchos amigos y eran los más traviesos y valientes de la Universidad que tenían por oficio hallarse en cuantos desconciertos y travesuras había en Alcalá, especialmente en maltratar a los ministros de justicia y hacerles burla.

La vida turbulenta entre la estudiantina procaz, de la que formaba parte destacada, le hizo pasar por graves situaciones con peligro para su libertad y para su misma vida. Situaciones que le hicieron reflexionar y volver a pedir su entrada en la Compañía.

A pesar de las muchas dificultades que sus historias le crearon para ser admitido y, probado a fondo, al final lo consiguió en 1561 a los 19 años.

Trabajó como hermano coadjutor, pues no quiso hacer estudios. Fue un procurador y gestor hábil en los asuntos para la Compañía.

A este mismo género de los valientes y traviesos pertenecía uno que era conocido en Alcalá en los últimos años del siglo XVI como «el Bachiller Nequitia»49.

«Había en esta Villa de Alcalá un estudiante tan en extremo travieso que traía revuelta la Villa porque casi cada noche tenía pendencia con los Alguaciles y otras gentes».

Una serie de circunstancias le pusieron en contacto con el rector de los jesuitas, Luis Guzmán que consiguió que hiciera los ejercicios con él en la misma casa de Alcalá. En estos ejercicios, al igual que tantos otros estudiantes, tuvo

${ }^{49}$ Cuenta su historia el P. Luis Guzmán que fue Rector del Colegio Complutense en 1594 y 1595, y la recoge Castro en su obra, pp. 838-839. Nequitia como es sabido significa maldad, perversidad. 
una notable conversión, pidió con mucha insistencia entrar en la Compañía de Jesús, y al fin lo consiguió, pero se dio de tal modo a las penitencias que peligró su salud mental y tuvo que abandonar el noviciado por imperativo de los médicos, aunque se conservó en una vida virtuosa, y terminó después su vida como religioso en otra orden.

\section{d) Criados y Artesanos}

En Alcalá había mucho servicio, era ocupación muy propia de aquella época y era una ciudad con mucho clero, bastante nobleza, y la universidad con su muchedumbre de Catedráticos y Maestros. Tengamos en cuenta, que muchos estudiantes, aun dentro de los colegios, tenían su servicio particular, generalmente de otros estudiantes. Bastantes de estos, entre ellos algunos de los que ya hemos mencionado, entraron en la Compañía de Jesús.

Como muestra de lo que decimos citamos a Duarte Pereyra, de nación portugués paje de Leonor de Mascareñas, fue uno de las primeras promociones que se incorporó ya en 1546, sufriendo por consiguiente las estrecheces y dificultades del patio de «Mataperros ${ }^{50}$.

Caso muy posterior y distinto es el de Julio Fuentes, no era estudiante, sino un aragonés trabajador de la construcción en Alcalá, ganando de comer por su trabajo alquilándose cada día por peón (...) para servir en algo a Nuestro Señor tomó por devoción sustentar a un estudiante pobre que después se recogiese a alguna religión y así partía con él su jornal. Entró en la Compañía de Jesús en 1556 (Castro, p. 506).

También dentro del ámbito de la construcción (aunque no de la pobreza) mencionaremos al Hermano Joanes de Loriaga, un vasco de Marquina, gran maestro de cantería que entró en 1570 trabajó como directivo en las obras de varias casas de la Compañía de Jesús como el colegio de Ocaña, el Noviciado de Villarejo, la casa de campo del Colegio de Alcalá, «Jesús del Monte» en Loranca, y sobre todo en la Iglesia de los jesuitas de Alcalá:

«comenzó desde sus fundamentos la magnífica Iglesia de este Colegio y la acabó en la perfección que al presente está y vio celebrar en ella los Divinos oficios poco más de dos meses con lo cual a lo que piadosamente pudo entenderse se lo llevó el Señor».

Murió a los 74 años en 1620 y fue el primer jesuita que fue enterrado en aquella iglesia que él mismo había construido ${ }^{51}$.

\footnotetext{
50 De Duarte de Pereyra nos habla Astráin, Ibidem, (I. 266) y Castro que le dedica más de media página y alaba su mortificación, humildad y devoción a Nuestra Señora, Ibidem, p. 62.

${ }^{51}$ EZQUERRA, Ibidem, pp. 423-424. 
Domingo Bertrán vitoriano y famoso escultor y retablista que entró el 21 de abril de 1561 y fue el que empezó el retablo de la Iglesia de los jesuitas en Alcalá que no pudo terminar por su fallecimiento el 27 de abril del año 1590.

Era ya ampliamente conocido en España y tiene un puesto importante en la escultura del siglo XVI. Castro comenta en su historia que «era extrañamente sencillo y por lo tanto muy amado de todos» y ya había hecho otros retablos en los colegios de Murcia y Madrid (Castro, p. 739).

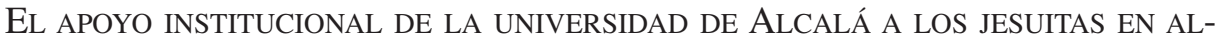
GUNOS PROBLEMAS GRAVES

Independientemente de la llamada que sintieron en estos años muchos estudiantes de la Universidad para entrar en la Compañía se pudo contar también con el apoyo institucional en algunas cuestiones generales, muchas de ellas de bastante gravedad. Nos referiremos a algunas de ellas, sin entrar a fondo en la problemática de de estos temas.

\section{a) Problema con el Arzobispo Siliceo}

La mayor fue la persecución que sufrieron de parte del Cardenal Arzobispo de Toledo, Juan Martínez Siliceo. Por su fuerte enemistad contra los jesuitas el arzobispo publicó en su diócesis de Toledo un edicto por el que se prohibía.

So pena de excomunión mayor latae sententiae a todos los curas, beneficiados y súbditos de su Arzobispado, que no admitiesen a ninguno de la Compañía a predicar, ni confesar, ni administrar sacramento alguno en sus Iglesias, ni se les diera recaudo para decir misa sin su licencia, y que revocaba cualesquiera licencias que hasta entonces les fueren dadas.

Dado el enorme poder del Arzobispo de la diócesis mayor, primada y más rica de España, se intentó por medio de personas poderosas, amigas de la Compañía, tanto en España como en Roma, que revocara el edicto. No se logró, ni siquiera por petición del pontífice 52 ; entonces los jesuitas recurrieron al Consejo real y también a la Nunciatura, además se movieron las influencias en Roma del P. Polanco y del mismo Ignacio. Siempre se tropezaba con la negativa del Arzobispo, que negaba la autoridad del Papa en este caso concreto, y la del Consejo Real, y

${ }^{52}$ La crisis de Siliceo viene muy largamente expuesta por Castro en su obra tan citada a lo largo de las pp. 153 a 227, la referencia a la Universidad está en la p. 216. Astráin también se refiere a esta crisis en su obra ya citada. Tomo I, pp. 356-362. 
del Emperador; porque les decía que estaban mal informados. Después de muchos intentos para resolver el asunto por las buenas, intervino el Nuncio, Cardenal Poggio, enviando primero una carta al Chantre de la Iglesia de San Yuste (Magistral de Alcalá) trasmitiéndole la orden del Papa Julio III de pedir un informe sobre los jesuitas al Rector de la Universidad y algunos doctores;

Tomando informe del Rector y algunos de los doctores y catedráticos de la dicha Universidad.

Este informe positivo y la negativa del Arzobispo a tenerlo en cuenta, aparte de las muchas y poderosas razones que ya antes se le habían dado, movieron al Nuncio a intimar bruscamente y con fuertes amenazas la orden del Papa.

Que dejase su reverencia a los de la Compañía, pues no eran sus ovejas, y si no que, por vida del Papa, que la mandaría preso a Roma.

Ante esta amenaza cedió de mala gana Siliceo. Siguió poniendo todas las trabas que podía a los jesuitas hasta su muerte, pero el edicto fue revocado y la Universidad de Alcalá tuvo su parte no pequeña en ello.

\section{b) La controversia sobre el Libro de los Ejercicios Espirituales}

Tuvo lugar también un serio problema con el libro de los Ejercicios Espirituales. de San Ignacio. Habían surgido inquietudes. Algunos creían ver en algunas de sus partes «desvaríos de herejes y alumbrados». No era cosa nueva, ya había surgido esa misma inquietud en París en 1527 y habían sido los ejercicios examinados a fondo y calurosamente aprobados por el inquisidor Ortí. Pero en 1547 en Toledo, con motivo de la actuación de seis piadosos sacerdotes que habían hecho los ejercicios bajo la dirección de Villanueva y los propagaban, volvieron a surgir acusaciones que llegaron a Alcalás3. Astráin habla de las conversaciones de Villanueva con el rector de la Universidad de Alcalá, el rector quedó satisfecho, Villanueva le rogó nombrase una comisión de doctores que dictaminara sobre el asunto, así se hizo en 1547 y también quedaron los doctores ampliamente satisfechos y alabaron el libro de los ejercicios ${ }^{54}$. Esto no im-

53 Astráin, Ibidem, tomo I, cap. $10^{\text {a }}$, p. 368.

54 Villanueva, el primer rector del Colegio Complutense pese a su escasa preparación básica, por puro carisma, llamó poderosamente la atención en Alcalá por su acierto de dar los ejercicios, lo que fue el determinante de muchas de las vocaciones de Alcalá y de otras conversiones y cambios de vida espectaculares de todo género de personas. Es oportuno referir unas palabras de $\mathrm{S}$. Ignacio en sus últimos años referentes a este entonces hermano Villanueva que nos han llegado en el Memorial de Luis Gonçalves da Cámara, n. 226. «Hablando de los Ejercicios decía que de los que conocía en la Compa-

Hispania Sacra, LXI

123, enero-junio 2009, 159-190, ISSN: 0018-215-X 
pidió que siguieran atacando al libro de los ejercicios algunos teólogos dominicos de fama, como Melchor Cano en Salamanca y Tomás de Pedroche en Toledo, pero la opinión favorable a los ejercicios acabó por imponerse tanto a las autoridades eclesiásticas, como en la práctica ordinaria y fructuosa de muchos fieles.

\section{c) La controversia llamada «de auxiliis»}

Fue larga, dura y finalmente no resuelta. Se trataba de armonizar la libertad humana con la gracia eficaz de Dios. La controversia se daba, fundamentalmente, entre teólogos dominicos, que se inclinaban más a la causalidad divina o gracia eficaz, y teólogos jesuitas que acentuaban la libertad humana. Las figuras más representativas fueron, por parte de los dominicos Fray Domingo Báñez, y por los jesuitas Luis de Molina.

La controversia se prolongó durante bastantes años y tuvo diversas alternativas, siempre dentro del mayor apasionamiento. Este asunto no llegó a resolver$\mathrm{se}^{55}$. Entre los años 1594 y 1598, El Papa Clemente VIII pidió un amplio y bien documentado informe a España, tanto a Dominicos, como a Jesuitas y también a la Inquisición y por medio de esta a bastantes Obispos y a las Universidades de Salamanca, Alcalá y Sigüenza. Salamanca se mantuvo neutral, se limitó a afirmar aquello que nadie dudaba sin entrar en el meollo de la discusión. Sigüenza se decantó claramente por la doctrina de los jesuitas más favorecedora de la libertad. Alcalá firmó su dictamen el 1 de octubre de 1596 y según la opinión de Astráin, "no hay duda de que favorece algo a la Compañía de Jesús»56.

Algunas actitudes POSITIVAS DEL CONJUNTO ESTUDIANTIL DE LA UNIVERSIDAD FRENTE A LOS JESUITAS

Independientemente de lo numeroso de las vocaciones surgidas entre los estudiantes de Alcalá, y de los diversos casos particulares, podemos referirnos a ciertos fenómenos de tipo religioso o social que nos permiten suponer la extensión que tenía entre los estudiantes una actitud positiva hacia la Compañía de Jesús.

\footnotetext{
ñía, el que mejor los daba era el P. Fabro, el segundo Salmerón, y después ponía a Francisco de Villanueva y a Jerónimo Doménech».

${ }^{55}$ Lo agudo de la controversia se prolongó de 1588 a 1607, año en que se dio libertad para seguir cualquiera de los dos sentencias y se prohibió por el Papa Paulo V que siguiera la discusión.

56 Astráin, Idem.
} 


\section{a) Los sermones en la Universidad}

Ya nos hemos referido arriba al impacto concreto y positivo que tuvieron en el ambiente de la Universidad los sermones del P. Araoz en 154757. Los jesuitas de Alcalá cuidaron mucho de buscar personas muy escogidas para los sermones que se predicaban para la Universidad preferentemente en San Ildefonso o en la Iglesia magistral de San Yuste. A ellos se hace referencia, en las Historias del Colegio Complutense de Castro y Ezquerra.

Los sermones, de predicadores escogidos, tuvieron un impacto claramente apreciable en las vocaciones de estudiantes.

\section{b) Otros datos de religiosidad sorprendentes}

Hay también otros datos igualmente sorprendentes en dicho colectivo; Astráin nos habla sobre disciplinas públicas para estudiantes que se tuvieron durante la cuaresma tres veces por semana. En el año 1572 participaron unos quinientos ${ }^{58}$, otro dato recogido por este mismo autor y referido al año 1582 habla de 700 estudiantes disciplinándose durante una recitación del Miserere ${ }^{59}$.

Independientemente de sus manifestaciones de religiosidad grupos de estudiantes demostraron también en ocasiones, cierta simpatía con los jesuitas de la ciudad. Tenemos un ejemplo curioso:

\section{c) Un ejemplo curioso: «Del ruido que hubo con la entrada de un caballero»}

En el año de 1571 entró en el noviciado de Alcalá un estudiante, caballero de Madrid, llamado D. Francisco de España, hijo de viuda, Doña Petronila de Varros «que había tenido oficio en casa del emperador». Por ello conservaba influencias en las alturas y por el mucho cariño que tenía al menor de sus hijos, quiso sacarlo del noviciado y consiguió para ello una provisión del Consejo Real, para que saliese porque suponía que había sido engañado por sus pocos años y querían que lo pensase mejor. Para ello recurrió al vicario del Arzobispo (algo pariente de ella) y este se presentó en la casa de los jesuitas para reclamar al novicio, con la provisión real, y acompañamiento de notarios y oficiales.

\footnotetext{
57 Astráin, Ibidem, tomo 1, p. 257. El P. Cristóbal de Mendoza, entonces colegial de Alcalá, comentando estos sermones de Araoz en la cuaresma de 1547 decía así: Tanta gente seguir al predicador aqui en esta universidad no así fácilmente se ve.

58 AsTRÁIN, Ibidem, tomo II, p. 522.

59 ASTRÁIN, Ibidem, tomo IV, p. 780. 
El novicio no quería abandonar su vocación de la que no dudaba y los superiores previendo lo que iba a suceder lo habían alejado provisionalmente de la casa de Alcalá. En esta casa se encontraba casualmente el P. Provincial y a él en persona le reclamó el vicario la entrega del novicio, se le respondió por el Provincial que dicho novicio se encontraba casualmente en Madrid. El vicario pidió y se le concedió registrar la casa, naturalmente no lo encontraron. Sospechando lo ocurrido, el vicario persistía en sus exigencias, se agrió la discusión y el vicario, fuera de sí insultó al Provincial y al sapientísimo P. Deza, catedrático de la Universidad que intentó mediar «al que llamó bachillerejo y otras palabras indignas de ser contadas».

El provincial con mesura y sosiego exponía que eran religiosos exentos y consiguientemente libres de la jurisdicción episcopal.

«Alguien tocó la campana y salieron luego un montón de hermanos de buenos cuerpos y fuerzas que a la menor señal del provincial...el cual por su mucha prudencia les hizo señas que ninguno se desmandase en la cosa menor del mundo».

Insistió el vicario en llevarse detenidos al Provincial y al P. Deza, El Provincial con humildad, pero siempre intimando las Bulas de la Compañía, aceptó ir adonde lo llevaran y salieron; pero ya había llegado mucha gente en su mayor parte estudiantes amigos de la Compañía que empezaban a aprestar sus espadas. El vicario ante esta situación desistió de llevarse preso al Provincial, sobre todo al ver la actitud amenazadora de los estudiantes que atestaban la calle ante la puerta.

«Estaban ya muchos apercibidos y con gran denuedo como empuñadas las espadas para embestir en el Vicario y en los de su compañía sin que pudiera el Provincial ni otro alguno de los nuestros resistirlos».

Tanto el Vicario como el Provincial enviaron sendos informes al Consejo Real cuyo presidente era el Cardenal Espinosa, el informe del Provincial fue el que prosperó y según el cronista todos los oidores se quedaron espantados de la audacia del vicario que tuvo que renunciar a sus pretensiones y al poco tiempo se fue volviendo gran amigo de la Compañía de Jesús ${ }^{60}$.

\section{SITUACIONES TIRANTTES ENTRE LOS JESUITAS Y LA UNIVERSIDAD}

Creemos que con los datos hasta ahora expuestos, se aprecia claramente una situación de buena armonía entre la Universidad y sus estudiantes, y la Compañía de Jesús y los suyos. A pesar de esta buena armonía no faltaron algunas situaciones tirantes o muy tirantes que es justo que expongamos.

\footnotetext{
${ }^{60}$ Castro dedica a este episodio un capítulo entero de su obra ya citada, pp. 1102 a 1106.
} 


\section{a) Protestas por algunas entradas en la Compañía}

Se dieron a veces protestas puntuales por el paso a la Compañía de Jesús de numerosos estudiantes, con los que a veces, la Universidad o el Colegio Mayor San Ildefonso contaban para otros fines.

Uno de estos episodios ocurrió en 1552 con motivo de la entrada en la Compañía de Jesús, de un joven estudiante muy brillante y habilidoso. Pedro de Falces, estudiante de Artes y discípulo del Doctor Aguilera61.

«En la entrada de este Hermano aconteció una cosa digna de contarse. Sintió, mucho su entrada el Rector, y la de otros muchos de la Universidad, pareciéndoles que las mejores habilidades se venían para la Compañía y que les habían de faltar para las cátedras lectores, y quisieron irse a quejar al Consejo Real, mas contentáronse por entonces con esta diligencia: Como supieron la pobreza que el Colegio tenía y con cuanta dificultad pagaba un censillo que debía al Colegio Mayor entraron en Claustro los Doctores y de él salió que se enviase este recaudo al P. Rector, que ellos sabían la pobreza que pasaban los Nuestros y que no podían pagar el censo que tenían sobre sus casas, que ellos les perdonarían si se obligaban a no recibir ninguno sin darles de ello aviso primero y pedir su parecer».

Villanueva no accedió, se negó en redondo y afirmó «que él procuraría pagar su censo» y consideró inaudita la misma proposición.

\section{b) Las «reparaciones» en el Colegio de los jesuitas}

Hubo otro contratiempo con la Universidad en el año de 1567. Enseñaba entonces en nuestro colegio el P. Deza inteligentísimo alcalaíno, nacido en 1530 . Había estudiado en la universidad y por la brillantez de sus estudios, manifestada en los diversos grados que fue adquiriendo se «opuso» y ganó cátedras en la misma universidad.

Sintió la llamada de Dios, y se decidió, no sin trabajo y seria reflexión, a entrar en la Compañía de Jesús el año de $1558^{62}$. Dado lo brillante de su situación académica, su entrada admiró a todos, pero fue respetada pues se conocía su madurez y altura personal en inteligencia y virtud.

Pero al llegar el año 1567 es nombrado Rector del Colegio de los jesuitas el P. Manuel López, este potenció algo que ya existía, las «reparaciones» o repeticiones en el Colegio Complutense de las doctrinas que antes los jesuitas habían oído en la

\footnotetext{
${ }^{61}$ CAstro, Ibidem, pp. 233-234.

62 Castro trata en obra ampliamente del P. Deza al que se dedica un capítulo entero entre las pp. 609 y 648 .

Hispania Sacra, LXI

123, enero-junio 2009, 159-190, ISSN: 0018-215-X
} 
Universidad63. Participó en esas «reparaciones» el P. Deza, y empezaron a coger fama y altura y asistir voluntariamente a ellas muchos estudiantes seglares de la Universidad, los cuales para hacerlo dejaban de asistir a las lecciones en la misma.

Esto motivó protestas en el profesorado de la Universidad, especialmente del doctor D. Alonso de Mendoza. Su clase de 10 a 11 de la mañana se despoblaba, pues muchos estudiantes se iban a oír al maestro Deza que a esa misma hora leía en el Colegio de los jesuitas. Por ello

«fue a la Corte y trajo una prohibición en que se mandaba que, en aquella hora que concurría con la Universidad no leyese».

Los estudiantes afectados, que eran muchos, protestaron vivamente, y llegaron a buscar un procurador y rellenar un pliego de protesta al Consejo real con firmas, etc. La cosa no fue adelante porque los superiores jesuitas no quisieron dar a la Universidad ocasión de división, y establecieron otro horario para esas reparaciones de 7 a 8 de la mañana; hora...bien incómoda y trabajosa especialmente en invierno, y con todo eso no fue menos frecuentada de todo género de religiosos y colegiales, teólogos y los demás estudiantes, que fue menester ensanchar el aula como ahora está y añadiéndola la aulilla que llaman y no bastaba, porque todo el zaguán se llenaba de gente; y porque algunas mañanas faltava (sic) la luz para escribir traían sus belas (sic) con las que se alumbraban de esta manera persevera hasta el día de hoy esta lección, pero ya no es tan frecuentada ${ }^{64}$.

\section{c) El Problema del Colegio Imperial}

Más profunda fue la oposición de la Universidad de Alcalá, que se unió a la de Salamanca ${ }^{65}$, con motivo de la fundación en 1627 del Colegio Imperial de los jesuitas en Madrid, en el que se intentó montar, entre otras materias, unos estudios de Filosofía, la oposición de estas dos potentes universidades, hizo que se tuviera que desistir de estos determinados estudios 66.

${ }^{63}$ Luis E. Rodríguez de SAN Pedro BeZAres, Ibidem, p. 495, se refiere a los problemas que se les creaba a las Universidades por los Colegios y Conventos vinculados que impartían clases a las que acudían no sólo sus propios alumnos sino a veces también los de la Universidad (en Calderón de la Barca y la España del barroco, de J. AlCALÁ ZAMORA).

${ }^{64}$ CASTRo, Ibidem, pp. 1027-1028. Hay que tener en cuenta que esta obra la redactó entre 1595 y 1599.

65 Ambas Universidades contaron con el apoyo decidido de la de Lovaina, ya que fueron visitadas ambas por Cornelio Jansenio profesor prestigioso en Lovaina y decidido enemigo de los jesuitas.

66 Sobre este tema puede verse AsTRÁIn, Ibidem, vol. V, pp. 139-170 y EZQUERRA, Ibidem, pp. 623 y ss. En la controversia intervinieron principalmente el canónigo doctor catedrático de Salamanca Juan de Balboa y el Dominico Fray Angel Manrique, y por parte de los jesuitas, el P. Fernando de Salazar y el P. Rodrigo Niño. Fuera de lo Universitario fue un episodio más de enfrentamiento entre jesuitas con 
No cabe duda que este episodio fue un grave contratiempo y es más de notar porque el prestigio sumado de las Universidades de Salamanca y Alcalá se impuso a la clara y abierta preferencia de la corona (Felipe IV, el Conde Duque de Olivares y el Cardenal Trejo, Presidente del Consejo de Castilla).

La presión se notó más en Salamanca, donde los jesuitas sufrieron grandes dificultades, que en Alcalá y así concluye Astráin:

«Observamos en general que los jesuitas gozaban de mayores simpatías en Alcalá que en Salamanca y tuvieron ordinariamente fervorosos amigos en la Universidad Complutense» 67 .

A este clima de simpatía y mutua estima entre la moderna Universidad de Alcalá y la naciente Compañía de Jesús en esta ciudad, junto con otros factores que hemos presentado en este artículo, se debe en buena parte el fenómeno de la entrada masiva en la Compañía de Jesús de tantos estudiantes y algunos profesores de la Universidad, que constituyeron una sólida base para la expansión de la orden tanto en España como en territorios europeos, todavía en aquellos siglos bajo una directa influencia de España.

\section{APÉNDICE}

En este Apéndice pormenorizamos el número de novicios que se suman a la Compañía de Jesús en Alcalá de Henares año por año. Disponemos de este número casi con exactitud matemática por los datos que figuran en la fuente principal que manejamos. No todos los entrados pertenecían a la Universidad, consta de algunos que no pertenecían a ella, pero por lo que se especifica de la mayoría de ellos y por el hecho de que tanto Castro como Ezquerra se refieren continuamente a la Universidad como la fuente de todas las vocaciones, podemos afirmar que en su mayoría eran universitarios.

No puede suponerse otra cosa tratándose de una ciudad de las dimensiones de la Alcalá. de estos años (dos o tres mil vecinos).

Nos limitamos a los datos que aparecen en las dos partes de la Historia del Colegio Complutense escritas por Francisco de Castro y Alonso Ezquerra.

Damos los datos año por año, indicando siempre el número de jesuitas y la página de la que se ha tomado el dato. A veces damos el nombre o hacemos algunas observaciones.

\footnotetext{
dominicos y otros religiosos, ya que, al margen de lo univesitario, hubo un fuerte ataque contra la Compañía de Jesús pero poco relacionado con la Universidad y los jesuítas de Alcalá.

${ }^{67}$ Astráin, Ibidem, vol. V, p. 153.

Hispania Sacra, LXI

123, enero-junio 2009, 159-190, ISSN: 0018-215-X
} 


\section{Datos de la primera parte de la Historia (1533-1599), autor P. Castro}

\begin{tabular}{|ll|}
\hline AÑO & ENTRADOS EN LA COMPAÑíA \\
\hline 1544 & Los dos primeros (Villanueva y Sevillano). \\
\hline 1546 & Entra uno Miguel de Torres. \\
\hline 1547 & Entran dos, Duarte Pereyra y Juan Pablo Álvarez. \\
\hline $1548-50$ & $\begin{array}{l}\text { Entran varios estudiantes a los que no se cita. Se dice que por falta de medios para } \\
\text { mantenerlos y alojarlos se les envía a otras casas de jesuitas como Gandía. No ca- } \\
\text { ben, se alquila un patio como para unos cinco (p. 69). Entra un portugués llamado } \\
\text { Tablares (p. 73). }\end{array}$ \\
$\begin{array}{ll}\text { Entran ocho estudiantes movidos por el buen ejemplo de los jesuitas (año 1548) } \\
\text { entre ellos Baptista de Barma y Juan Gomero. (p. 124). }\end{array}$ \\
\hline $1550-51$ & Entran 12 después de la predicación de Estrada (p. 130). \\
\hline 1551 & Entran muchos de la universidad, sólo se menciona como ejemplo a cuatro. (p. 164). \\
\hline 1552 & Entran 6. (p. 233). \\
\hline 1553 & $\begin{array}{l}\text { Entran en la Compañía 25; se habla de los más eminentes, casi todos alumnos de } \\
\text { artes, teología o del trilingüe, (p. 259). }\end{array}$ \\
\hline 1554 & Entran 14 entre ellos dos doctores en Teología (p. 333). \\
\hline 1555 & Entran 40 (p. 346). \\
\hline 1556 & $\begin{array}{l}\text { Este año no se dice cuantos entraron pero se mencionan y se dan más o menos } \\
\text { apuntes biográficos de 16 en p. 506 y ss. }\end{array}$ \\
\hline 1557 & Entran 10 «elegidos entre muchos que pidieron» (p. 602). \\
\hline 1558 & Entraron 34 (p. 672). \\
\hline 1560 & Entran 9 (p. 683). \\
\hline 1561 & $\begin{array}{l}\text { Entran 5 (p. 739). } \\
\text { Endias, se hablaba de ello a comienzos del 61 pero la patente se le dio en 1562 }\end{array}$ \\
\hline 1562 & Pueron recibidos 12 por los sermones del P. Doctor Antonio Madrid. \\
\hline 1564 & Por los sermones del P. Doctor Govierno entran 9 (p. 886). \\
\hline
\end{tabular}

${ }^{68}$ Comienza ese año el generalato de Laínez después de dos años vacantes por la muerte de Ignacio, El P. Nadal convocó a una reunión, en Alcalá, a varios padres de los más importantes. Su entrada en España tuvo problemas (páginas 747 y 748), Nadal encuentra dificultades serias para sus actividades y aun permanencia en España. Las dificultades vienen de las altas esferas de la nación, desde las cuales practicamente se impide con fuertes presiones que el P. Araoz vaya destinado a Roma, como deseaban los superiores, por lo cual se le nombra Comisario de España e Indias, con lo que se quedaba en Madrid.

${ }^{69}$ En AstrÁIN tomo 2, 144-146, se narran las dificultades entre Araoz por una parte (con sus amplias influencias en el gobierno de España por medio de Ruy Gómez de Silva),y Nadal y Borja, por otra. Puede que aquí esté la clave de que no haya habido entradas (o no se hayan reseñado) en 1562. 


\begin{tabular}{|c|c|}
\hline AÑO & ENTRADOS EN LA COMPAÑÍA \\
\hline 1565 & Entran 11, por los fervores con los estudiantes que muchos se movían (p. 909). \\
\hline 1566 & Movidos por el P. Govierno y la comunicación con los nuestros entran 17, (p. 922). \\
\hline 1567 & Por los sermones del P. Ramírez entran 20 (p. 951). \\
\hline 1568 & $\begin{array}{l}\text { P. } 1028 \text { fueron recibidos hasta } 23 \text { (sermones del P. Ramírez, el cronista comenta } \\
\text { cierta liberalidad en recibir) entre ellos un Maestro que acababa de ser admitido } \\
\text { como colegial mayor y } 6 \text { licenciados y tres caballeros. }\end{array}$ \\
\hline 1569 & $\begin{array}{l}\text { P. } 1068 \text {. Entran } 29 \text { por los sermones del P. Govierno, trato con nuestros estudian- } \\
\text { tes y liberalidad del provincial. }\end{array}$ \\
\hline 1570 & P.1096. Entran 38., de los que 35 son estudiantes de la Universidad. \\
\hline 1571 & P.1098. Entran 44. Por el buen ejemplo de los nuestros. \\
\hline 1572 & P. 1123. Fueron recibidos 46 (de ellos 40 estudiantes). \\
\hline 1573 & P. 1136 Entran 24. \\
\hline 1574 & P. 1180 «casi dos docenas, [pongamos 22]. \\
\hline 1575 & P. 1182 fueron recibidos 12 . \\
\hline 1576 & P. 1199 fueron recibidos 18 . \\
\hline 1577 & P. 1201, fueron recibidos 12 . \\
\hline 1578 & P. 1203 fueron recibidos 8 . \\
\hline 1579 & P. 1204 fueron recibidos 10 . \\
\hline 1580 & Entran 9 (p. 1227). \\
\hline 1581 & Entran 5 (p. 1228). \\
\hline 1582 & Entran 18. (1228). \\
\hline 1583 & Entran 15 (1228). \\
\hline 1584 & Entran 17 (1229). \\
\hline 1585 & Entran 7 (1230). \\
\hline 1586 & Entran 7 (1230). \\
\hline 1587 & Entran 7 (1231). \\
\hline 1588 & Entran 13 (1231). \\
\hline 1589 & Entran 22 (1233). \\
\hline 1590 & Entran 17 (p. 1233). \\
\hline 1591 & Entran 6 (p. 1234). \\
\hline 1592 & Entran 12 (p. 1234). \\
\hline 1593 & Entran 3 (p. 1234). \\
\hline 1594 & Entran 7 (p. 1235). \\
\hline 1595 & Entran 5 (p. 1236). \\
\hline 1596 & Entran 3 (p. 1236). \\
\hline
\end{tabular}




\begin{tabular}{|ll|}
\hline AÑO & ENTRADOS EN LA COMPAÑ́íA \\
\hline 1597 & Entran 3 (p. 1237). \\
\hline 1598 & Entran 21 (p. 1237) (los nombres de todos) \\
\hline 1599 & Entran 22 (p. 123). \\
\hline
\end{tabular}

\section{Datos de la segunda parte de la Historia. 1600-1633, autor P. Ezquerra}

En esta parte disminuye algo el número de vocaciones, aunque sigue siendo muy elevado. Son relacionados nominalmente todos y se suele dedicar a todos unas líneas, con su edad, procedencia (diócesis) y algunos pocos datos. En bastantes hay reseñas amplias o muy amplias, con capítulos enteros, o varios capítulos.

\begin{tabular}{|c|c|}
\hline AÑO & ENTRADOS EN LA COMPAÑÍA \\
\hline 1600 & Entran 7 (p. 4 ). \\
\hline 1601 & Entran 9 (p. 12). \\
\hline 1602 & Entran 14 (11 estudiantes y 3 coadjutores) (p. 16). \\
\hline 1603 & Entran 8 (p. 119). \\
\hline 1604 & Entran 6 (p. 124). \\
\hline 1605 & Entran 10 (p. 136). \\
\hline 1606 & Entran 5 (p. 155). \\
\hline 1607 & Entran 11 (pp. 165-172). \\
\hline 1608 & Entran 6 (pp. 179). \\
\hline 1609 & Entran 18 (p. 193). \\
\hline 1610 & Entran 16 (pp $211 \mathrm{ss})$. \\
\hline 1611 & Entran 17 (pp 225 ss). \\
\hline 1612 & Entran 7 (pp. 235 ss). \\
\hline 1613 & Entran 14 (p. 247 ss). \\
\hline 1614 & Entran 10 (p. 261 ss). \\
\hline 1615 & Entran 19 (p. 293 ss). \\
\hline 1616 & Entran 8 (p. 322 y ss). \\
\hline 1617 & Entran 22 (p. 334 ss). \\
\hline 1618 & Entran 16 (p. 245 ss). \\
\hline 1619 & Entran 22 (p. 375 ss). \\
\hline 1620 & Entran 12 (p. 419 ss). \\
\hline
\end{tabular}




\begin{tabular}{|ll|}
\hline AÑO & ENTRADOS EN LA COMPAÑ̃́A \\
\hline 1621 & Entran 10 (p. 440 ss). \\
\hline 1622 & Entran 23 (p. 447 ss). \\
\hline 1623 & Entran 12 (p. 532 ss). \\
\hline 1624 & Entran 7 (p. 541). \\
\hline 1625 & Entran 3 (y salen enseguida dos) (p. 546). \\
\hline 1626 & Entran 9, \\
\hline 1626 & Entran 10 (p. 579). \\
\hline 1627 & Entran 14 (p. 600). \\
\hline 1628 & Entran 11 (p. 665). \\
\hline 1629 & Entran 6 (p, 683). \\
\hline 1630 & Entran 14, (12 estudiantes y dos coadjutores) (p. 704). \\
\hline 1631 & $\begin{array}{l}\text { Entran 5. Por penuria económica y las devaluaciones. Hay «numerus clausus» (li- } \\
\text { mitación del número de admisiones por orden superior) (p. 711). }\end{array}$ \\
\hline 1632 & Entran 4. sigue el numerus clausus, (p. 725). \\
\hline 1633 & Entran 4 (p. 734). \\
\hline
\end{tabular}

\section{Resumen general de los entrados en la Compañía de Jesús de Alcalá entre 1545 y 1634}

\begin{tabular}{|l|l|c|c|}
\hline Periodo & Fuente & $\mathbf{N}^{\mathbf{0}}$ de entradas & Media anual \\
\hline Entre 1545 y 1599 & $\begin{array}{l}\text { (Primera parte de la Historia del } \\
\text { Colegio Complutense) }\end{array}$ & 765 & 13,9 anual \\
\hline Entre 1600 y 1633 & $\begin{array}{l}\text { (Segunda parte de la Historia del } \\
\text { Colegio Complutense) }\end{array}$ & 425 & 11,9 anual \\
\cline { 2 - 4 } & Total ambos periodos & $\mathbf{1 . 1 9 0}$ & $\mathbf{1 3 , 4}$ anual \\
\cline { 2 - 4 }
\end{tabular}

\section{BIBLIOGRAFÍA ESPECÍFICA}

Aguadé NiETo, Santiago (coord). Cisneros y el siglo de Oro de la Universidad de Alcalá, Alcalá de Henares, Fundación General de la Universidad de Alcalá, 1999.

Alcalá-Zamora, J., Calderón de la Barca y la España del Barroco, Madrid, Centro de Estudios Políticos y Constitucionales, 2001. 
Aldea, Quintín, Martín, T., Vives, J., Diccionario de Historia Eclesiástica de España. Voz «Universidades», Madrid. CSIC 1972.

Astráin, Antonio, Historia de la Compañía de Jesús en la Asistencia de España.Tomos 1, 2, 4. 5. Madrid, Sucesores de Ribadeneyra, 1902 y 1905.

BAngert, W., Historia de la Compañía de Jesús, Santander editorial Sal Terrae, 1981.

CAstro, P., Cristóbal de., Historia del Colegio Complutense de la Compañía de Jesús. 2.vol. 1548-1600, Alcalá de Henares, Compluti 1600 (manuscrito).

Domínguez OrTiZ, A., Iglesia y Estado en el siglo XVII. Estudios de Historia Económica y Social de España, Universidad Granada, Biblioteca de Bolsillo, 1987.

Entrambasaguas, Joaquín de., Grandeza y Decadencia de la Universidad Complutense, Madrid, Editorial Complutense, 1996.

Ezquerra S. J. P. Alonso., Historia del Colegio Complutense de la Compañía de Jesús $2^{a}$ parte 1600-1633, Compluti (Alcalá de Henares), Manuscrito 1633.

García Villoslada, Ricardo, San Ignacio de Loyola Nueva Biografía, Madrid, Biblioteca de autores Cristianos, 1986.

GuTIÉRREZ TORRECILla, Miguel, Libro de matrícula de la Universidad de Alcalá en "Cisneros y el Siglo de Oro de la Universidad de Alcalá», de AGUADÉ NIETO, S., (coord.), Alcalá de Henares, Editorial de la Universidad de Alcalá, 1999.

Marchamalo, A., Marchamalo, M., Sanz de Diego, R. Mª., Guía Ignaciana de Alcalá de Henares, Alcalá de Henares, Institución de Estudios Complutenses y Provincia de Toledo de la Compañía de Jesús, 1990.

Martínez Millán, J. (Dir), La Corte de Felipe II, Madrid, Edición Alianza Universitaria, 1994.

Martínez Millán, J., Familia Real y grupos políticos. La princesa. Doña Juana de Austria, Madrid, Edición Alianza Universitaria, 1994.

Nieremberg, E. y ANDRAde, A., Varones ilustres de la Compañía de Jesús. Tomo VIII Toledo, Bilbao, Editorial Mensajero, segunda edición, 1891.

Olivares, Estanislao, Diccionario Histórico de la Compañía de Jesús. Hermanos coadjutores, Madrid, Institutum Historicum Societatis Jesu y Universidad de Comillas, 2001.

Olivari, Michelle, Entre el Trono y la Opinión, Salamanca, Junta de Castilla y León, Concejalía de Cultura y Turismo, 2004. 
O’NeILl, Charles S. J. y Domínguez, Joaquín S. J., Diccionario Histórico de la Compañía de Jesús, Madrid-Roma, Institutum Historicum Societaris Jesu y Universidad Pontificia Comillas, 2001.

Peset, José Luis y Hernández SANDoica, Elena, Estudiantes de Alcalá, Alcalá de Henares, Excmo Ayuntamiento de Alcalá de Henares, 1984.

Portilla, D. Miguel de, Historia de la ciudad de Compluto, 2.vol (facsímil), Alcalá de Henares, Editado por Josef Espartola, 1725.

Quevedo, Francisco de, Historia de la vida del Buscón, Madrid, EspasaCalpe, Colección Austral, novena edición, 1964.

Quintano Ripollés, Alfonso, Historia de Alcalá de Henares, Alcalá de Henares, Exscmo Ayuntamiento de Alcalá de Henares, 1973.

Rodríguez-SAn Pedro BeZAres, Luis Enrique, La Universidad del Barroco o de la Monarquía católica, Madrid, Centro de Estudios Políticos y Constitucionales, Universidad de Salamanca, 2001.

Tellechea Idígoras, I.,Tiempos Recios, Salamanca, Universidad Pontificia de Salamanca, 2004.

Tornero, Anselmo Raymundo, Datos históricos de la ciudad de Alcalá de Henares, Alcalá de Henares, 1950.

Torremocha, Margarita, La vida estudiantil en el Antiguo Régimen, Madrid, Alianza Editorial, 1998.

Verdoy, S. J., Alfredo, «El Jesuita Padre Francisco Villanueva (15091557)», Manresa 68 (1996), pp. 405-428. 